\title{
Closed Form Confidence Intervals for Small Sample Matched Proportions
}

James F. Reed III

Christiana Care Hospital System, Newark, Delaware, JaReed@ChristianaCare.org

Follow this and additional works at: http://digitalcommons.wayne.edu/jmasm

Part of the Applied Statistics Commons, Social and Behavioral Sciences Commons, and the Statistical Theory Commons

\section{Recommended Citation}

Reed, James F. III (2009) "Closed Form Confidence Intervals for Small Sample Matched Proportions," Journal of Modern Applied Statistical Methods: Vol. 8 : Iss. 2 , Article 15.

DOI: $10.22237 /$ jmasm/1257034440

Available at: http://digitalcommons.wayne.edu/jmasm/vol8/iss2/15 


\title{
Closed Form Confidence Intervals for Small Sample Matched Proportions
}

\author{
James F. Reed III \\ Christiana Care Hospital System, \\ Newark, Delaware
}

The behavior of the Wald-z, Wald-c, Quesenberry-Hurst, Wald-m and Agresti-Min methods was investigated for matched proportions confidence intervals. It was concluded that given the widespread use of the repeated-measure design, pretest-posttest design, matched-pairs design, and cross-over design, the textbook Wald-z method should be abandoned in favor of the Agresti-Min alternative.

Key words: Matched proportions, Wald-z, Wald-c, Quesenberry-Hurst, Wald-m, Agresti-Min.

\section{Introduction}

Matched-pairs data are common in clinical trials. Study designs that use paired data include the repeated-measure design, pretest-posttest, the matched-pairs design, and the cross-over design. When the response variable is dichotomous and when two dichotomous measurements are available, the data may be summarized as shown in Table 1.

Table 1: Paired Data Study Design Responses

\begin{tabular}{|c|c|c|c|}
\cline { 2 - 4 } \multicolumn{1}{c|}{} & \multicolumn{3}{c|}{ Test II } \\
\hline Test I & Success & Failure & Total \\
\hline Success & $\mathrm{a}$ & $\mathrm{b}$ & $\mathrm{a}+\mathrm{b}$ \\
\hline Failure & $\mathrm{c}$ & $\mathrm{d}$ & $\mathrm{c}+\mathrm{d}$ \\
\hline Total & $\mathrm{a}+\mathrm{c}$ & $\mathrm{b}+\mathrm{d}$ & $\mathrm{n}$ \\
\hline
\end{tabular}

For binary responses, McNemar's test is the most commonly applied significance test for comparing the two response distributions. For interval estimation of the difference of proportions, textbooks present the Wald large sample interval (Wald-z). Like the one proportion (Figure 1) and the difference between

James F. Reed III, Ph.D., is a Senior Biostatistician. Email him at: JaReed@ChristianaCare.org. two independent binomial confidence intervals (Figure 2), the Wald-z interval for matched-pair proportions behaves rather poorly (Figure 3a). Two problems are generally encountered. First, the coverage probability cannot be achieved exactly and secondly, in many instances the Wald-z method does not yield sensible intervals.

The purpose of this study was to investigate the coverage probability of alternative methods for computing confidence intervals to the typical textbook Wald-z or Wald-c (continuity correction). Those alternatives include a simple add four method proposed by Agresti and Min (AM) (2005), a method by Quesenberry and Hurst (QH) (1964), and a modified Wald (Wald-m) suggested by May and Johnson (1998).

\section{Methodology}

Notation and Computational Formula

Let $\mathbf{y}=(\mathrm{a}, \mathrm{b}, \mathrm{c}, \mathrm{d})^{\mathrm{T}}$ represent the observed frequencies for a sample from a multinomial distribution with underlying probabilities $\pi=\left(\pi_{\mathrm{a}}, \pi_{\mathrm{b}}, \pi_{\mathrm{c}}, \pi_{\mathrm{d}}\right)^{\mathrm{T}}$. Let $\mathrm{b}$ be the number of subjects who respond favorably on the first occasion but unfavorably on the second and let $\mathrm{c}$ be the number who responds unfavorably on the first occasion but favorably on the second. Let a be the number of subjects who respond favorably on both occasions and let $\mathrm{d}$ be the number who respond unfavorably on both occasions; then $\mathrm{a}+\mathrm{d}$ represents the number of concordant pairs and $b+d$ represents the number of discordant pairs. 
Figure 1: Coverage Probabilities $(n=50)$ for A Single Proportion Wald Confidence Interval Method

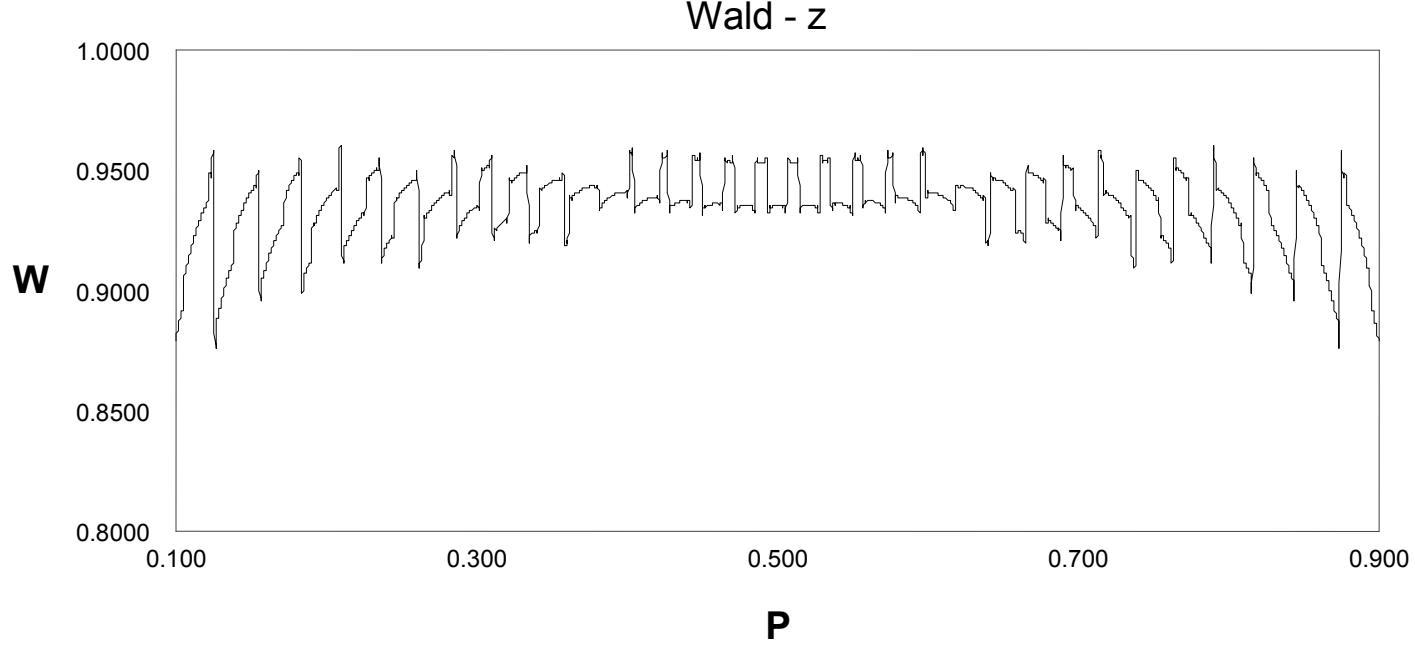

Figure 2: Coverage probabilities for the difference in nominal $95 \%$ Wald-z as a function of $\mathrm{p}_{1}$ when $\mathrm{p}_{2}=0.3$ with $\mathrm{n}_{1}=\mathrm{n}_{2}=20$ (Two Independent Proportions)

Wald-z

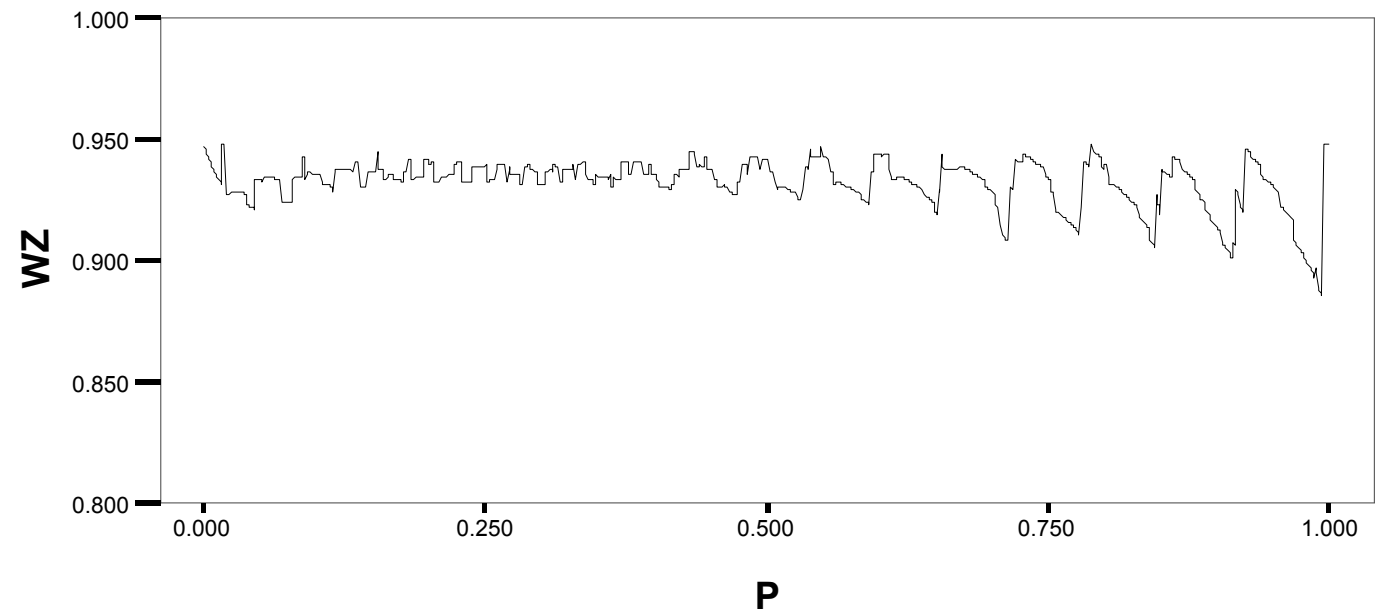

The confidence interval computational methods based on the data structure given in Table 1 are as follows:

Wald-z:

$$
\mathrm{LB}=(\mathrm{b}-\mathrm{c}) / \mathrm{n}-\mathrm{z}_{\alpha 2} \sqrt{\left.\left[\left((\mathrm{b}+\mathrm{c}) / \mathrm{n}-(\mathrm{b}-\mathrm{c})^{2}\right) / \mathrm{n}^{2}\right) / \mathrm{n}\right]}
$$

and

$$
\mathrm{UB}=(\mathrm{b}-\mathrm{c}) / \mathrm{n}+\mathrm{z}_{\alpha 2} \sqrt{\left.\left[\left((\mathrm{b}+\mathrm{c}) / \mathrm{n}-(\mathrm{b}-\mathrm{c})^{2}\right) / \mathrm{n}^{2}\right) / \mathrm{n}\right]} .
$$

Wald-c:

$$
\begin{aligned}
\mathrm{LB}= & (\mathrm{b}-\mathrm{c}) / \mathrm{n} \\
& -\left\{\frac{\mathrm{z}_{\alpha 2} \sqrt{\left.\left[\left((\mathrm{b}+\mathrm{c}) / \mathrm{n}-(\mathrm{b}-\mathrm{c})^{2}\right) / \mathrm{n}^{2}\right) / \mathrm{n}\right]}+1}{\mathrm{n}}\right\}
\end{aligned}
$$

and

$$
\begin{aligned}
\mathrm{UB}= & (\mathrm{b}-\mathrm{c}) / \mathrm{n} \\
& +\left\{\frac{\mathrm{z}_{\alpha 2} \sqrt{\left.\left[\left((\mathrm{b}+\mathrm{c}) / \mathrm{n}-(\mathrm{b}-\mathrm{c})^{2}\right) / \mathrm{n}^{2}\right) / \mathrm{n}\right]}+1}{\mathrm{n}}\right\} .
\end{aligned}
$$

Wald-m: 
$\mathrm{LB}=\left|\mathrm{p}_{\mathrm{b}}-\mathrm{p}_{\mathrm{c}}\right|-\left\{\chi^{2}\left[\left(\mathrm{p}_{\mathrm{b}}+\mathrm{p}_{\mathrm{c}}+1 / \mathrm{n}\right)-\left(\mathrm{p}_{\mathrm{b}}-\mathrm{p}_{\mathrm{c}}\right)^{2}\right] / \mathrm{n}\right)^{1 / 2}$

and

$\mathrm{UB}=\left|\mathrm{p}_{\mathrm{b}}-\mathrm{p}_{\mathrm{c}}\right|+\left\{\chi^{2}\left[\left(\mathrm{p}_{\mathrm{b}}+\mathrm{p}_{\mathrm{c}}+1 / \mathrm{n}\right)-\left(\mathrm{p}_{\mathrm{b}}-\mathrm{p}_{\mathrm{c}}\right)^{2}\right] / \mathrm{n}\right)^{1 / 2}$

with

$$
\chi^{2}=\chi^{2}(\alpha, 1)
$$

Quesenberry-Hurst (QH):

$$
\mathrm{LB}=\frac{\left(\mathrm{n}\left|\mathrm{p}_{\mathrm{b}}-\mathrm{p}_{\mathrm{c}}\right|\right)}{\left(\frac{\left(\chi^{2}+\mathrm{n}\right)-\left\{\chi^{2}\left[\left(\chi^{2}+\mathrm{n}\right)\left(\mathrm{p}_{\mathrm{b}}+\mathrm{p}_{\mathrm{c}}\right)-\mathrm{n}\left(\mathrm{p}_{\mathrm{b}}-\mathrm{p}_{\mathrm{c}}\right)^{2}\right]\right\}^{1 / 2}}{\left(\chi^{2}+\mathrm{n}\right)}\right)}
$$

and

$$
\mathrm{UB}=\frac{\left(\mathrm{n}\left|\mathrm{p}_{\mathrm{b}}-\mathrm{p}_{\mathrm{c}}\right|\right)}{\left(\frac{\left(\chi^{2}+\mathrm{n}\right)+\left\{\chi^{2}\left[\left(\chi^{2}+\mathrm{n}\right)\left(\mathrm{p}_{\mathrm{b}}+\mathrm{p}_{\mathrm{c}}\right)-\mathrm{n}\left(\mathrm{p}_{\mathrm{b}}-\mathrm{p}_{\mathrm{c}}\right)^{2}\right]\right\}^{1 / 2}}{\left(\chi^{2}+\mathrm{n}\right)}\right)}
$$

where

$$
\chi^{2}=\chi^{2}(\alpha, 1)
$$

Agresti-Min (AM):

$$
\begin{aligned}
\mathrm{LB}= & \left(\mathrm{c}^{*}-\mathrm{b}^{*}\right) / \mathrm{n}^{*} \\
& -\mathrm{z}_{\alpha 2} \sqrt{\left[\left(\mathrm{b}^{*}+\mathrm{c}^{*}\right)-\left(\mathrm{c}^{*}-\mathrm{b}^{*}\right)^{2} / \mathrm{n}^{*}\right] / \mathrm{n}^{*}}
\end{aligned}
$$

and

$$
\begin{aligned}
\mathrm{UB}= & \left(\mathrm{c}^{*}-\mathrm{b}^{*}\right) / \mathrm{n}^{*} \\
& -\mathrm{z}_{\alpha, 2} \sqrt{\left[\left(\mathrm{b}^{*}+\mathrm{c}^{*}\right)-\left(\mathrm{c}^{*}-\mathrm{b}^{*}\right)^{2} / \mathrm{n}^{*}\right] / \mathrm{n}^{*}}
\end{aligned}
$$

with

$$
b^{*}=b+1 / 2, c^{*}=c+1 / 2, n^{*}=n+2 .
$$

The joint probability mass function of $\left(\mathrm{Y}_{\mathrm{b}}, \mathrm{Y}_{\mathrm{c}}\right)$ is expressed as a function of $\Delta\left[\Delta=\left(\pi_{\mathrm{c}}-\pi_{\mathrm{b}}\right)-\left(\pi_{\mathrm{a}}-\right.\right.$ $\left.\left.\pi_{\mathrm{c}}\right)=\pi_{\mathrm{b}}-\pi_{\mathrm{c}}\right]$ and is given by: $\mathrm{f}\left(\mathrm{b}, \mathrm{c} \mid \Delta, \pi_{\mathrm{c}}\right)=\operatorname{Pr}$ $\left(\mathrm{Y}_{\mathrm{b}}=\mathrm{b}, \mathrm{Y}_{\mathrm{c}}=\mathrm{c} \mid \Delta, \pi_{\mathrm{c}}\right)=\mathrm{n} ! /[\mathrm{b} ! \mathrm{c} !(\mathrm{n}-\mathrm{b}-\mathrm{c}) !]\left(\pi_{\mathrm{c}}+\right.$ $\Delta)^{\mathrm{b}} \pi_{\mathrm{c}}^{\mathrm{c}}\left(1-2 \pi_{\mathrm{c}}-\Delta\right)^{\mathrm{n}-\mathrm{b}-\mathrm{c}}$. Where, $\Delta$ and $\pi_{\mathrm{c}}$ satisfy the following inequality:

and

$$
\pi_{\mathrm{c}} \in[-\Delta,(1-\Delta) / 2] \text { if }-\Delta<\pi_{\mathrm{c}}<0 .
$$

Coverage probability $(\mathrm{CP})$ is generally used to evaluate $(1-\alpha)$ confidence intervals. The coverage probability function $\mathrm{CP}(\Delta)$ for matched proportions for any $\Delta$ is defined as:

$$
\mathrm{CP}(\Delta)=\left[\Sigma_{\mathrm{k}}\left[\Sigma_{\mathrm{b}} \Sigma_{\mathrm{c}} \mathrm{I}_{\mathrm{T}}\left(\mathrm{b}, \mathrm{c} \mid \Delta, \pi_{\mathrm{c}}\right) \mathrm{f}\left(\mathrm{b}, \mathrm{c} \mid \Delta, \pi_{\mathrm{c}}\right)\right]\right\},
$$

where:

$$
\mathrm{I}_{\mathrm{T}}\left(\mathrm{b}, \mathrm{c} \mid \Delta, \pi_{\mathrm{c}}\right)=1 \text { if } \Delta \in\left[\Delta_{\mathrm{l}}, \Delta_{\mathrm{u}}\right] ; 0 \text { otherwise. }
$$

\section{Results}

The $95 \%$ CP $(\Delta)$ for $\mathrm{p}_{\mathrm{c}}=0.1, \mathrm{n}=20$ and $\mathrm{p}_{\mathrm{b}}=$ $0.001, \ldots, 0.999$ for the Wald-z, Wald-c, AM, Wald-m and Quesenberry-Hurst methods are shown in Figure 3.

$\mathrm{CP}(\Delta)$ probabilities are $0.9125,0.9545$, $0.9401,0.9435$ and 0.0541 respectively. The $95 \% \mathrm{CP}(\Delta)$ for $\mathrm{p}_{\mathrm{c}}=0.25, \mathrm{n}=30$ and $\mathrm{p}_{\mathrm{b}}=0.001$, ..., 0.999 for the Wald-z, Wald-c, AM Wald-m and Quesenberry-Hurst methods are shown in Figure 4.

CP $(\Delta)$ probabilities are $0.9334,0.9611$, $0.9425,0.9484$ and 0.9448 respectively. And, the $\mathrm{CP}(\Delta)$ for $\mathrm{p}_{\mathrm{c}}=0.40, \mathrm{n}=40$ and $\mathrm{p}_{\mathrm{b}}=0.001, \ldots$, 0.999 for the Wald-z, Wald-c, AM Wald-m and Quesenberry-Hurst methods are shown in Figure 5. CP $(\Delta)$ probabilities are $0.9390,0.9607$, $0.9444,0.9485$ and 0.9451 respectively.

The CP $(\Delta)$ plots in figures 3-5 demonstrate that the Wald-z method is suboptimal over the range of $p$, the Wald-c and Wald-m methods are conservative and the Quesenberry-Hurst and Agresti-Min methods are slightly less than nominal.

\section{Conclusion}

A number of closed form methods for constructing confidence intervals for paired binary data were proposed. Newcombe (1998) conducted an empirical study to compare the CP $(\Delta)$ of ten confidence interval estimators for the difference between binomial proportions based on paired data. He concluded that the profile likelihood estimator and the score test based confidence interval proposed by Tango (1998) performed well in large-sample situations. May 
Figure 3: 95\% Coverage Probability for Matched Proportions

$\mathrm{p}_{\mathrm{c}}=0.1, \mathrm{n}=20 \mathrm{p}_{\mathrm{b}}=0.001, \ldots, 1-\mathrm{p}_{\mathrm{c}}$

Wald-z

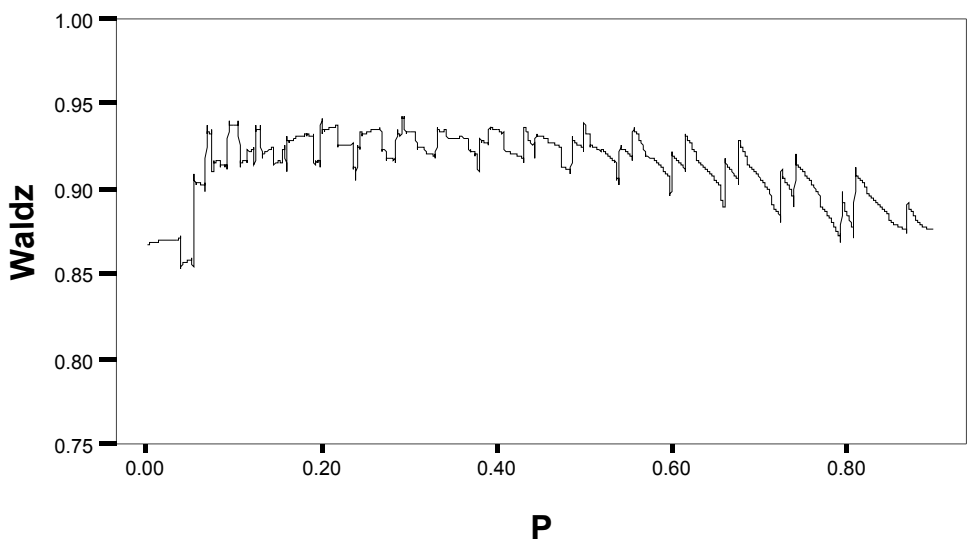

Wald-c

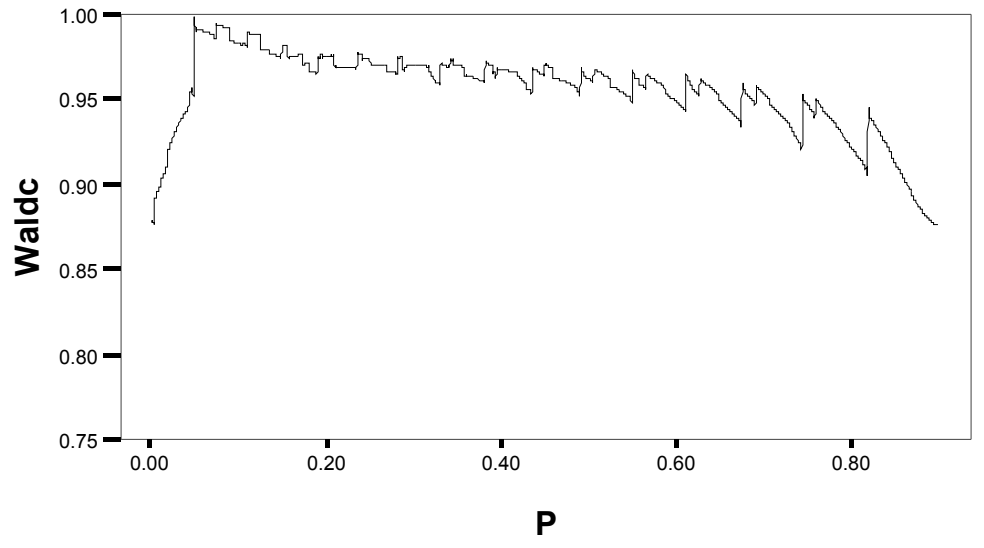

Wald-m

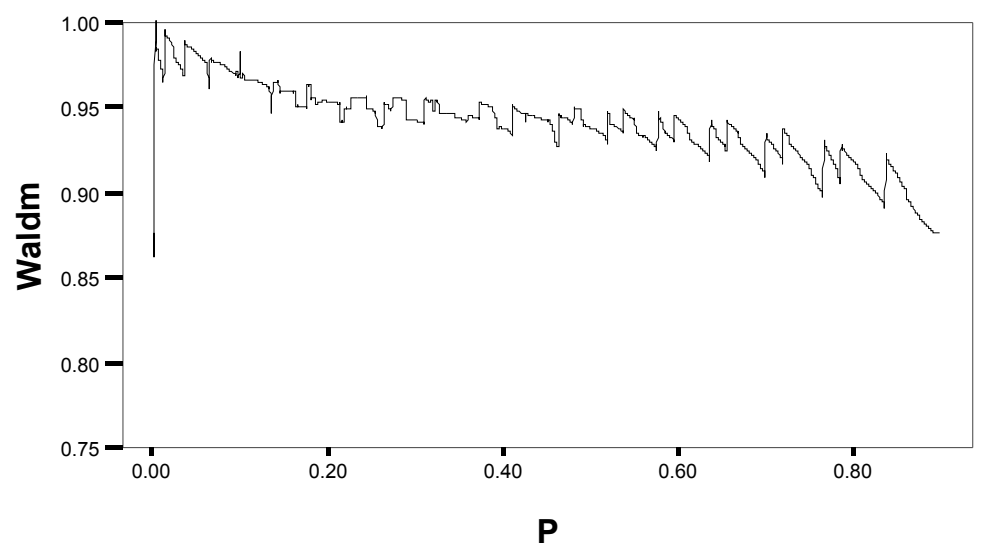


Figure 3 (continued): 95\% Coverage Probability for Matched Proportions

$$
\mathrm{p}_{\mathrm{c}}=0.1, \mathrm{n}=20 \mathrm{p}_{\mathrm{b}}=0.001, \ldots, 1-\mathrm{p}_{\mathrm{c}}
$$

\section{Quesenberry-Hurst}

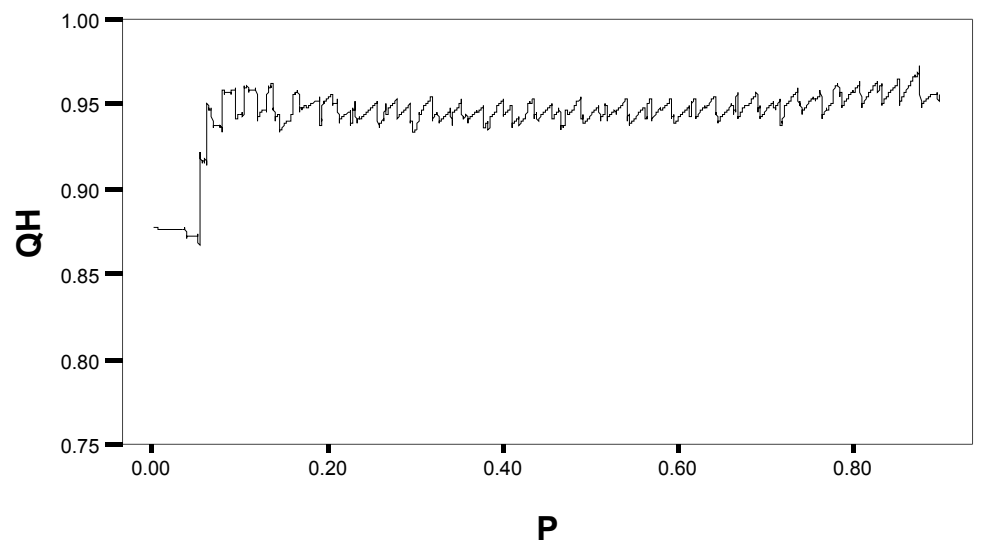

Agresti-Min

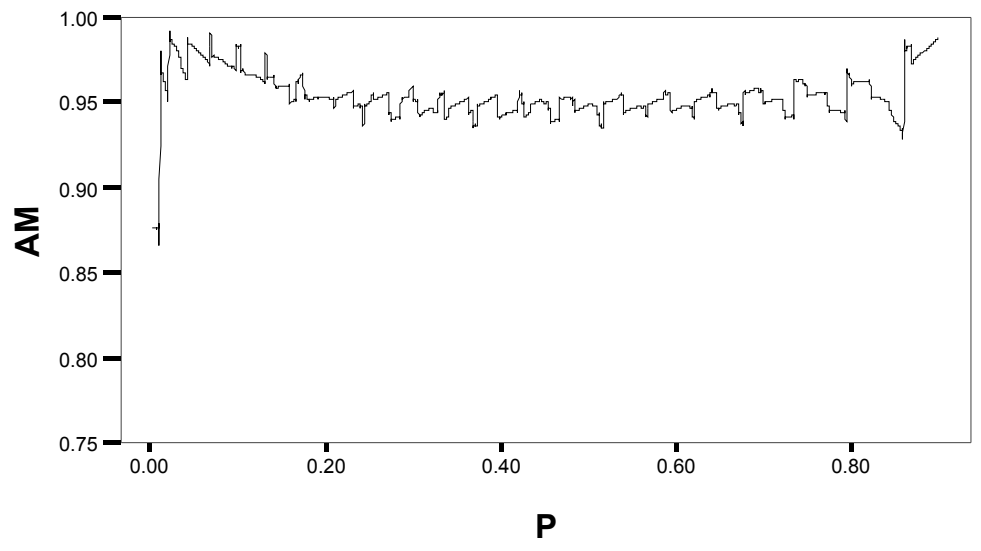

Wald-z

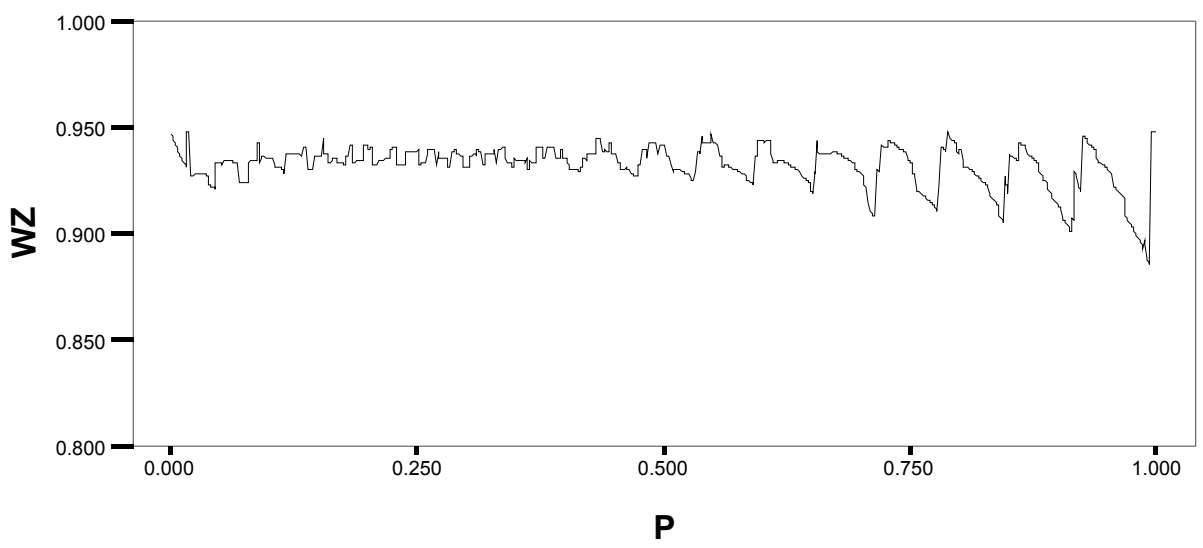


Figure 4: 95\% Coverage Probability for Matched Proportions

$\mathrm{p}_{\mathrm{c}}=0.25, \mathrm{n}=30, \mathrm{p}_{\mathrm{b}}=0.001, \ldots, 1-\mathrm{p}_{\mathrm{c}}$

Wald-z

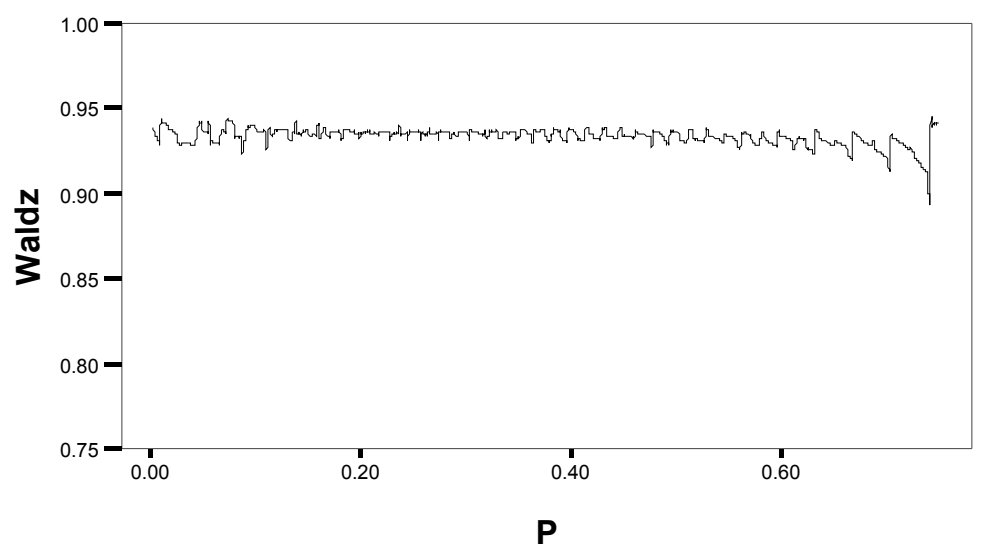

Wald-c

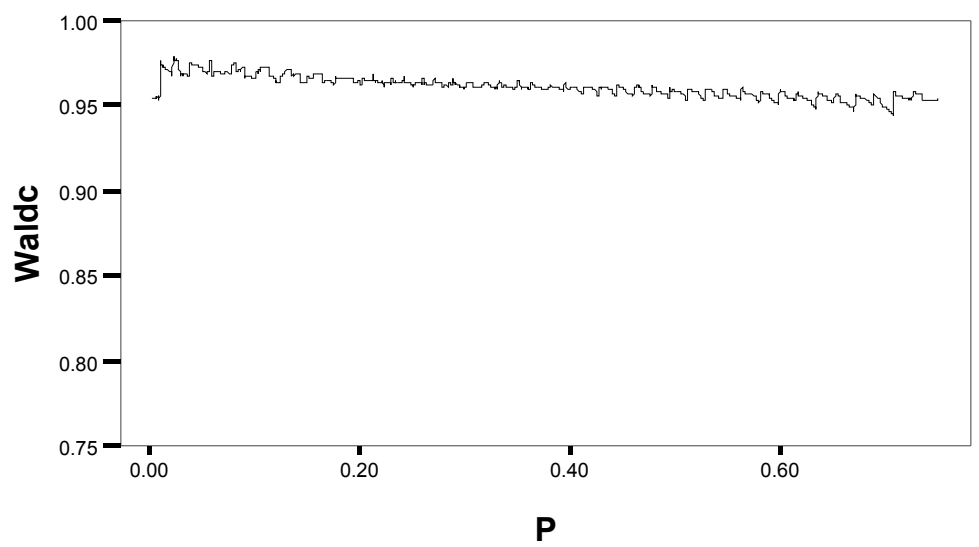

Wald-m

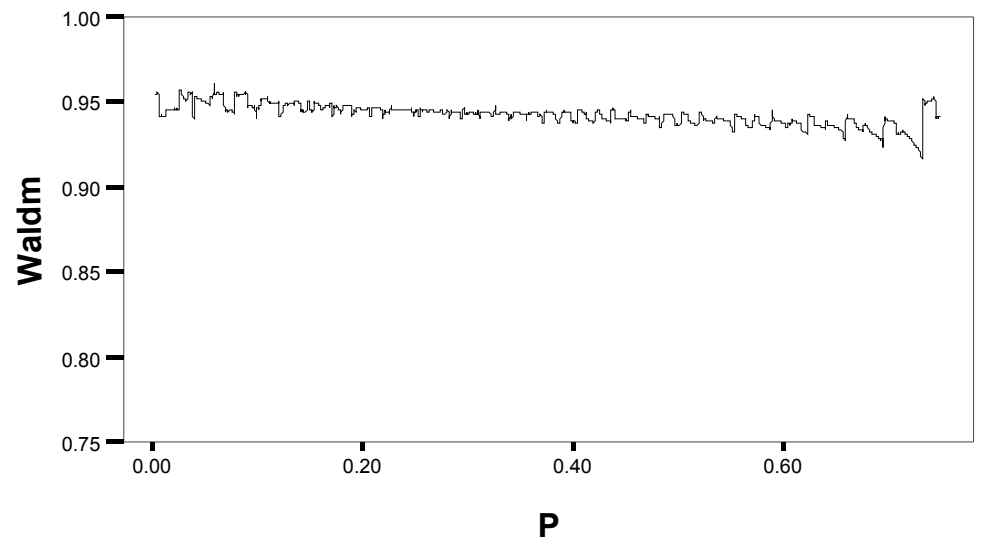


Figure 4 (continued): 95\% Coverage Probability for Matched Proportions $\mathrm{p}_{\mathrm{c}}=0.25, \mathrm{n}=30, \mathrm{p}_{\mathrm{b}}=0.001, \ldots, 1-\mathrm{p}_{\mathrm{c}}$

Quesenberry-Hurst

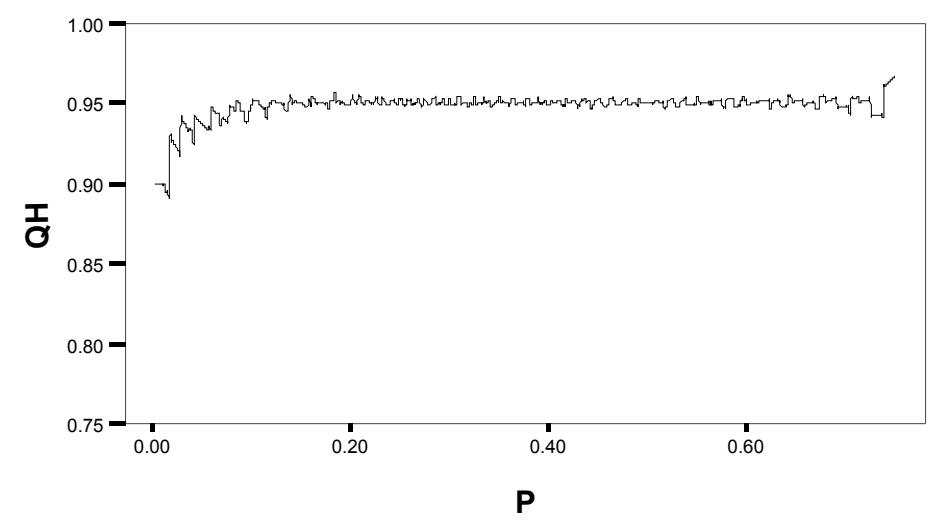

Agresti-Min

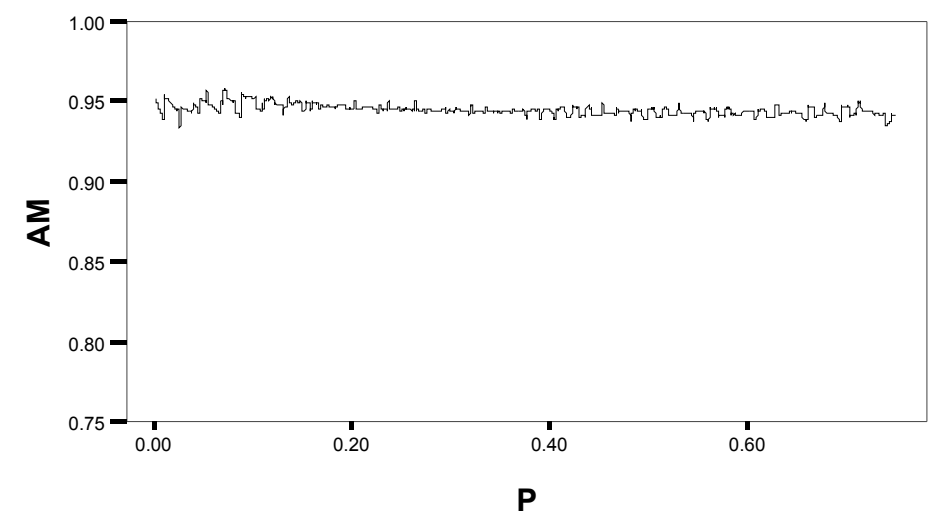

Figure 5: 95\% Coverage Probability for Matched Proportions

$\mathrm{p}_{\mathrm{c}}=0.4, \mathrm{n}=40$ and $\mathrm{p}_{\mathrm{b}}=0.001, \ldots, 1-\mathrm{p}_{\mathrm{c}}$

Wald-z

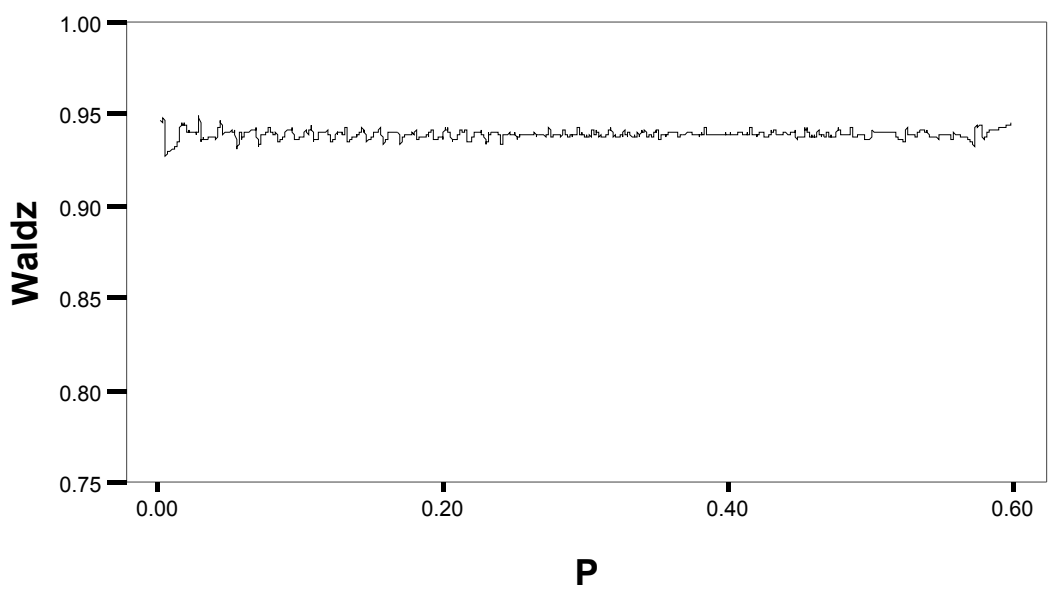


Figure 5 (continued): 95\% Coverage Probability for Matched Proportions $p_{c}=0.4, n=40$ and $p_{b}=0.001, \ldots, 1-p_{c}$

Wald-c

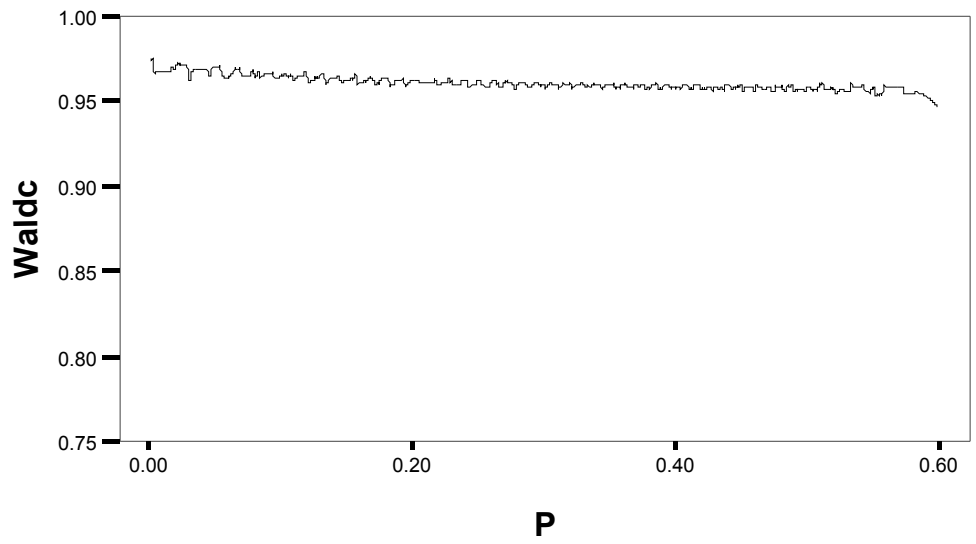

Wald-m

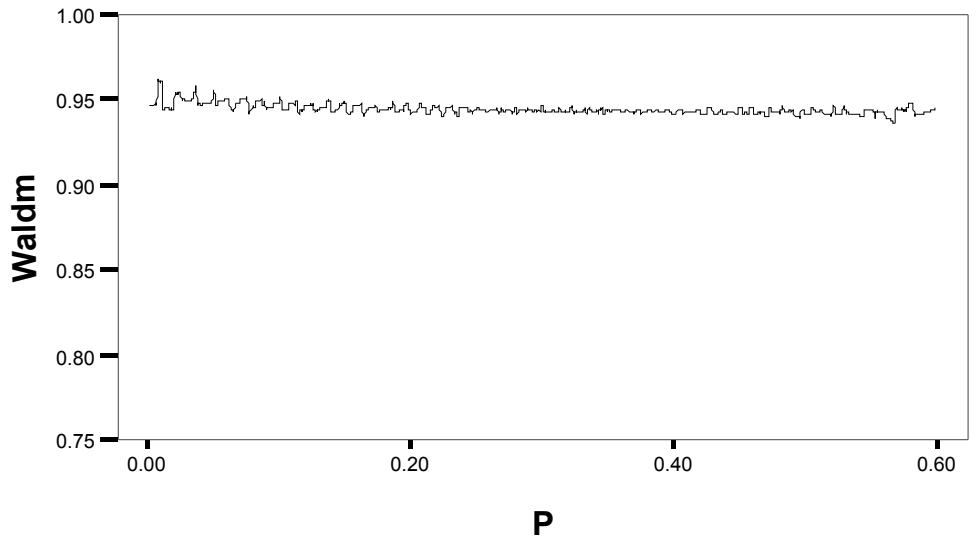

Quesenberry-Hurst

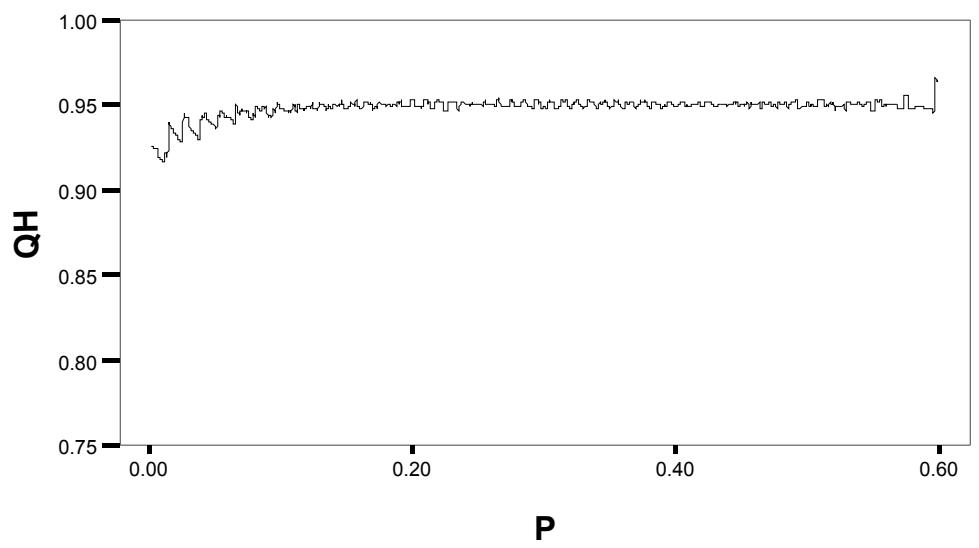


Figure 5 (continued): 95\% Coverage Probability for Matched Proportions $\mathrm{p}_{\mathrm{c}}=0.4, \mathrm{n}=40$ and $\mathrm{p}_{\mathrm{b}}=0.001, \ldots, 1-\mathrm{p}_{\mathrm{c}}$

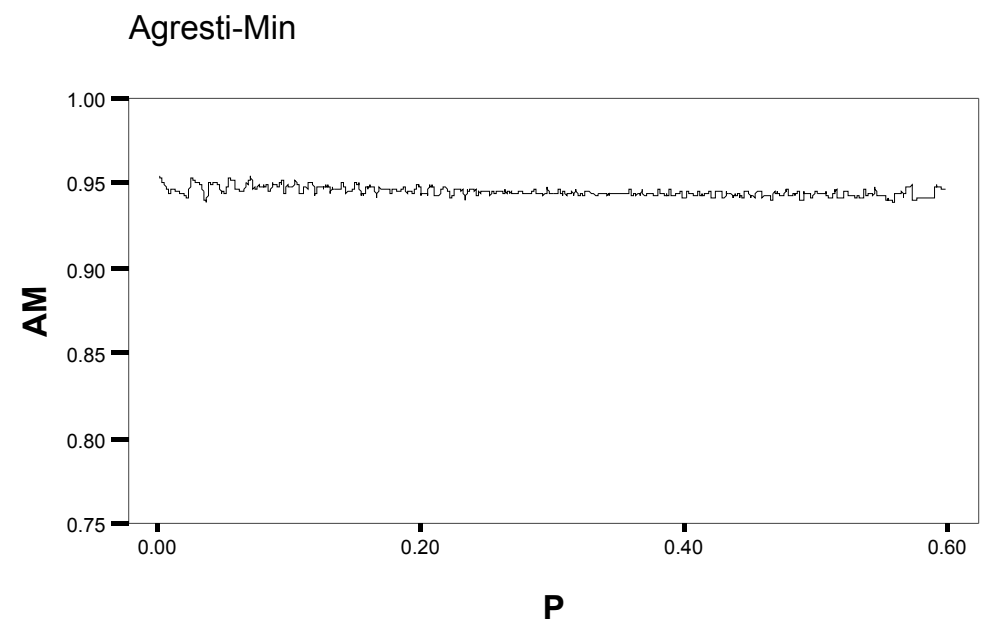

and Johnson (1998), Quesenberry and Hurst (1964) and Agresti and Min (2005) proposed closed form computationally friendly alternatives.

This article focused on constructing confidence intervals using closed form methods for paired data under small-sample designs. In this setting, based on the results, either the Quesenberry-Hurst or Agresti-Min methods are recommended. Given the widespread use of the repeated-measure, pretest-posttest, the matchedpairs, and the cross-over designs, the textbook Wald-z method should be abandoned in favor of either the closed form of Quesenberry-Hurst or Agresti-Min.

\section{References}

Agresti, A. \& Min, Y. (2005). Simple improved confidence intervals for comparing matched proportions. Statistics in Medicine, 24, 729-740.
Newcombe, R. G. (1998). Improved confidence intervals for the difference between binomial proportions based on paired data. Statistics in Medicine, 17, 2635-2650.

May, W. L., \& Johnson, W. D. (1998). Confidence intervals for differences in correlated binary proportions. Statistics in Medicine, 16, 2127-2136.

Quesenberry, C. P., \& Hurst, D. C. (1964). Large sample simultaneous confidence intervals for multinomial proportions. Technometrics, 6, 191-195.

Tango, T. (1998). Equivalence test and confidence interval for the difference in proportions for the paired-sample design. Statistics in Medicine, 17, 891-908. 